\title{
CINCO PREGUNTAS A ROBERT ALEXY ${ }^{1}$
}

The author of Theory of Fundamental Rights answers five questions that are debated in Colombia, concerning those rights, their interpretation, the act of balancing them, their compatibility with lawmaking decisions, and their relevance and scope in an armed conflict.

1. Profesor Alexy: en sus escritos hay una defensa de la ponderación en derecho constitucional. Usted la considera compatible con la noción de la Constitución como marco de acción para el legislador. ¿Por qué imponerle al legislador la tarea de ponderar entre un derecho fundamental afectado y la medida que busca proteger otro derecho o algún interés colectivo diverso? ¿No es una restricción indebida al poder democrático que ese legislador encarna?

-"Se debe distinguir entre la necesidad de la ponderación a la hora de establecer lo que los Derechos Fundamentales le permiten al legislador, y la pregunta acerca de si el legislador, en el margen de acción que los Derechos Fundamentales le conceden, debe ponderar. Ante la pregunta acerca de si el legislador admite una determinada ley, debe examinarse si dicha ley viola los derechos fundamentales, lo cual incluye el examen de su proporcionalidad; y la cuestión de la proporcionalidad no puede ser contestada sin ponderación. Al confirmarse que una ley se encuentra en el margen de acción del legislador, se plantea la gran pregunta, hasta hoy no resuelta, sobre cuáles serían los estándares de racionalidad que el legislador habría de satisfacer en sus márgenes de acción. Si realmente se trata de un margen de acción, debo decir que el legislador no está obligado a ponderar, pues la ponderación pretende determinar los límites de su libertad. Dentro del margen de libertad, sin embargo, puede tomar decisiones".

\footnotetext{
${ }^{1}$ Precedente agradece a Robert Alexy su amabilidad al conceder esta entrevista y al revisar y aprobar el texto de la misma. La entrevista fue hecha por Diana Patricia Quintero, profesora del programa de Derecho de la Universidad Icesi y miembro del Comité editorial de Precedente. Colaboró amablemente, como intérprete, Carlos Bernal Pulido. La trascripción de la entrevista y la traducción del texto en Alemán fueron hechas por Ilse König de Laverde.
} 
2. Los debates sobre las fuentes del derecho encierran una lucha por el poder. En Colombia, concretamente, se discute el valor del precedente constitucional como fuente primaria o como simple criterio auxiliar de interpretación normativa y esta discusión tiene las características de un debate sobre quién ha de ejercer el poder político de interpretación de los derechos fundamentales. iEs posible defender el carácter de fuente primaria de las decisiones del tribunal constitucional, sin que ello implique caer en lo que usted llama "sobreconstitucionalización"?

-"Al observar las diversas constituciones y tribunales constitucionales en el mundo, se advierte que el carácter prejudicial de las decisiones de la corte constitucional está reglamentado de dos maneras distintas. Una consiste en la regulación jurídico-positiva del carácter prejudicial. Este es el caso en Alemania. Allí, para numerosas decisiones del Tribunal Constitucional se encuentra establecida una vigencia normativa en el parágrafo 31 de la Ley del Tribunal Constitucional Federal. Donde tal reglamentación jurídico-positiva no existe, se plantea el problema general del carácter prejudicial. Hay diversas razones para un carácter prejudicial. La primera es de naturaleza altamente abstracta. Es la idea de la igualdad o de la justicia. Si un caso anterior ha sido resuelto de determinada manera, todo caso posterior que presente las mismas características debe ser resuelto de igual manera. Naturalmente, este efecto prejudicial a partir de la idea de la igualdad a manera de justicia formal, o incluso con base en el precepto de la igualdad en la Constitución, no es vinculante en el sentido estricto, ya que con una buena argumentación siempre se puede divergir de un concepto prejudicial. Eso es el overruling.

Existe, sin embargo, otra razón para atribuir un carácter prejudicial a las decisiones de la corte constitucional: las constituciones son regulaciones escuetas y en extremo abstractas. Desde ellas, la ponderación abre muchas posibilidades en cada caso particular. Precisamente a causa de la necesidad de ponderar en el derecho constitucional, especialmente en la interpretación de los derechos fundamentales, y precisamente a causa de la indefinición relacionada con eso, la vinculación prejudicial es indispensable como instrumento de compensación, con el fin de crear seguridad jurídica. Lo expuesto puede resumirse en la breve fórmula: ponderación supone precedente judicial [Präjudiz].

Y añado algo más: se debe evitar la sobreconstitucionalización, desde luego. Pero el medio adecuado para evitar una sobreconstitucionalización no es la eliminación del vínculo prejudicial. Al contrario, es justamente en el precedente judicial donde se habrán de destacar cuáles márgenes de acción y libertades tiene el legislador. Por eso necesitamos los precedentes, 
que dicen cuál es la amplitud de los márgenes de acción del legislador. Con eso el legislador tiene una libertad asegurada".

3. En un conflicto armado interno como el colombiano, colisionan derechos fundamentales, como el derecho a la libertad personal o a la libre circulación, con el derecho a la paz, en tanto derecho de los ciudadanos. Debido al carácter prioritario del derecho a la paz, se toman medidas de excepción que restringen esos otros derechos fundamentales. A causa de la gravedad del conflicto, esas restricciones podrían pasar el test de idoneidad, de necesidad y de proporcionalidad en sentido estricto y, además, lograr un gran respaldo popular. iHay algo en su teoría de los márgenes de acción que sirva de dique o freno a esa tendencia?

-"Eso depende de la manera como se interpreta la libertad general de acción. Por eso, sólo podré responder a la pregunta cuando sepa qué es la libertad general de acción según la Constitución colombiana. Quiero indicar por qué planteo esta cuestión: en Alemania, el artículo que garantiza la libertad general de acción se interpreta de dos maneras. Por una parte, garantiza la libertad de acción en calidad de derecho general a la protección de la personalidad y lo hace en asocio con la garantía de la dignidad humana. Paralelamente se responde por la libertad general de acción como libertad de hacer o dejar de hacer cualquier cosa a voluntad. Se advierte de inmediato que la libertad general de acción como expresión del derecho común de protección a la personalidad tiene un mayor peso abstracto que la libertad general de acción como derecho de hacer y dejar de hacer lo que se desee, por ejemplo, para decidir cómo uno quiere hacerse cortar el pelo. Por eso debo saber cuál es el significado de "libertad general de acción" en la Constitución colombiana para poder contestar la pregunta que me hizo".

[Después de recibir una concisa información sobre el artículo 16 de la Constitución, que protege el libre desarrollo de la personalidad, y sobre otras garantías constitucionales que tienen en vista la dignidad humana, Robert Alexy retoma su respuesta]

"En este caso mi respuesta será muy sencilla: tan pronto como entra en juego la dignidad humana, en relación con la libertad general de acción, se tiene una clara barrera. Mientras se trata solamente de decisiones cotidianas, que no tienen que ver con la personalidad, con la dignidad, sino con pequeñas ventajas y desventajas, también de tipo financiero, que no afectan la personalidad, tal preferencia prima facie a favor del derecho a la paz podría hacerse valer". 
4. Cuando en la Constitución económica hay pautas de desarrollo que van en sentido contrario, o en varios sentidos contradictorios entre sí, ino resulta superflua la teoría de los márgenes de acción?

-"Esa es una pregunta muy interesante y su contestación requiere de un cuidadoso análisis. Aquí no le puedo dar más que una respuesta provisional. Es cierto, en general, que una ley, y por tanto también una constitución, que alberga exigencias contradictorias, otorga a sus destinatarios una mayor libertad que una ley o constitución que no contiene contradicciones. Si la Constitución Colombiana rezara claramente: la Constitución Económica de Colombia es meramente capitalista o libertaria, entonces el legislador no tendría ningún margen de acción, pues sería evidente que todo debería ser capitalista. Igualmente, si la Constitución Colombiana dijera: Colombia es un estado socialista, el asunto sería claro, pues el legislador estaría obligado a crear una legislación socialista. Pero si en la Constitución constara que Colombia es no sólo capitalista sino también socialista, existirían muchas posibilidades y gran variedad de opciones para cumplir con tales pautas contradictorias, siempre y cuando se entendiera por "contradictorio" no una contradicción estrictamente lógica -que debe ser eliminada mediante la derogación de una norma - sino una situación de tensión jurídica entre principios objetivos de una constitución".

5. Usted ha definido los derechos fundamentales como mandatos de optimización que ordenan que algo se realice en la mayor medida posible, en relación con las posibilidades fácticas y jurídicas. Pero a menudo, esas posibilidades son interpretadas por legisladores y jueces constitucionales de manera distinta, digamos, desde distintos paradigmas jurídicos y económicos. La pregunta es: ¿Qué plantea el constitucionalismo democrático ante esta dificultad?

-"Esta pregunta tiene una parte sencilla y otra difícil. La parte sencilla se refiere a las posibilidades fácticas. El concepto de lo fáctico puede ser entendido de manera muy amplia. En mi definición de los principios, sin embargo, lo concibo de modo relativamente estricto, es decir, con respecto a la relación entre medio y fin. Se trata en este contexto de las posibilidades fácticas en el ámbito de la comprobación de la proporcionalidad, o sea, de la pregunta fáctica de si un medio que el legislador quiere aplicar, en primer lugar es en general idóneo para lograr su propósito, y, en segundo lugar, si hay un medio alternativo, de intervención menos profunda. En pocas palabras, la remisión a las posibilidades fácticas se refiere a lo que los economistas llaman "optimalidad de Pareto". Al haber delimitado el concepto de lo fáctico de esa manera, muchas cosas que en el lenguaje cotidiano designan lo fáctico - como por ejemplo lo económicamente deseable o ideas similares, o la socialización o la resocialización del hombre - entran, 
como fines, a la segunda categoría, la de las posibilidades jurídicas. Aquí, los aspectos culturales, morales y económicos, además de los legales, en todo caso juegan, a primera vista, un considerable papel. Un análisis más detenido, sin embargo, lleva a la conclusión de que todos los puntos de vista relevantes para lo normativo, que juegan un papel en el último nivel de la proporcionalidad, deben pasar por un filtro. Este filtro es el filtro de la relevancia jurídica. Cuando consideraciones normativas de índole moral juegan un papel, el sistema judicial debe haber incorporado o transferido estos estándares morales al sistema judicial. Eso puede llevarse a cabo mediante un correspondiente acto jurídico. Entonces, se ordena jurídicamente que el aspecto moral en cuestión sea tenido en cuenta, lo cual atribuye al aspecto moral validez jurídica formal. Algo similar ocurre con los aspectos culturales $\mathrm{u}$ otros.

Un punto importante en la teoría de los márgenes de acción es el siguiente: el legislador puede hacer suya una determinada política en razón de su poder de restringir derechos fundamentales. Esta facultad de restringir derechos fundamentales transforma los fines que el legislador elige por razones políticas, en razones de relevancia jurídica. Por eso puedo decir que para la proporcionalidad en un sentido estricto, en vista de la pregunta sobre la finalidad jurídicamente posible, sólo las razones jurídicamente relevantes juegan un papel y que, por consiguiente, el sistema jurídico puede ser comprendido como filtro contra otras consideraciones. En todo eso importa naturalmente - que si entonces concebimos la noción de derecho de manera tan amplia como yo lo hago-, entran en juego múltiples -la tesis de los casos excepcionales- argumentos morales y de conveniencia, pero no entran en juego como argumentos morales de cualquier índole, o como argumentos de conveniencia, sino como argumentos que el derecho exige que sean tenidos en cuenta. Con ello, el derecho mantiene el control sobre lo que en la ponderación puede jugar un papel, sin perjuicio de su apertura hacia otras esferas". 